\title{
MATHEMATICAL MODEL OF A WIDE CLASS MEMORY OSCILLATORS
}

R.I. Parovik, Vitus Bering Kamchatka State University, Petropavlovsk-Kamchatskiy, Russian Federation; Institute of Cosmophysical Research and Radio Wave Propagation FEB RAS, Paratunka, Russian Federation, romanparovik@gmail.com

A mathematical model is proposed for describing a wide class of radiating or memory oscillators. As a basic equation in this model is an integro-differential equation of Voltaire type with difference kernels - memory functions, which were chosen by power functions. This choice is due, on the one hand, to broad applications of power law and fractal properties of processes in nature, and on the other hand it makes it possible to apply the mathematical apparatus of fractional calculus. Next, the model integro-differential equation was written in terms of derivatives of fractional Gerasimov - Caputo orders. Using approximations of operators of fractional orders, a non-local explicit finite-difference scheme was compiled that gives a numerical solution to the proposed model. With the help of lemmas and theorems, the conditions for stability and convergence of the resulting scheme are formulated. Examples of the work of a numerical algorithm for some hereditary oscillators such as Duffing, Airy and others are given, their oscillograms and phase trajectories are constructed.

Keywords: mathematical model; Cauchy problem; heredity; derivative of fractional order; finite-difference scheme; stability; convergence; oscillograms; phase trajectory.

\section{Introduction}

In the paper of the Italian mathematician Vito Volterra [1], the notion of heredity (memory), a property of a dynamical system characterized by non locality in time, is introduced, which consists in the dependence of its current state on a finite number of previous states. V. Volterra investigated the hereditary oscillator - a vibration system with memory, which was written in the form of an integro-differential equation with a difference kernel, a function of memory. Further, for such an oscillator, Volterra derived the law of total energy, in which an additional term appeared, responsible for the dissipation of energy in the vibrational system. This fact was confirmed in subsequent works.

In papers [2-9] fractal oscillators were considered, which represent the class of hereditary oscillators with a power-law function of memory. The peculiarity of such oscillators is that their mathematical description can be reduced to differential equations with non-local derivatives of fractional constant orders, which are investigated within the framework of the theory of fractional calculus [10].

In papers $[2,4-7,9]$ models of fractal linear oscillators were investigated in the sense of the Gerasimov - Caputo derivative, and in papers $[3,8]$ - in the sense of the Riemann Liouville derivative. Analytical solutions of model equations in terms of a special function of Mittag - Leffler type and generalized Wright-type function, oscillograms and phase trajectories are constructed. It is shown that in the regime of free oscillations, the presence of memory effects in the system leads to attenuation of oscillations as a result of energy dissipation, and with allowance for external periodic action, it is possible to stabilize the amplitude of the oscillations, with the phase trajectories reaching the limit cycle and also the resonance effect. 
In a monograph by the Slovak mathematician I. Petras [3], the fractal nonlinear oscillator models whose differential equations contained fractional derivatives in the sense of Riemann - Liouville were considered and analyzed using numerical methods and considered the stability of the rest point of oscillatory systems. However, the stability and convergence of numerical methods have not been considered.

A further continuation of the investigation of hereditarity oscillators is associated with the introduction of the derivatives of fractional variable orders in the model equations. This is due to the fact that the orders of fractional derivatives are related to the properties of the medium in which this or that process takes place and changes with time under the influence of external influence. Therefore, papers [5-9] proposed the models of fractal nonlinear oscillators were proposed and investigated using explicit finite-difference schemes, whose equations contain both the derivatives of the constants, and variable fractional orders of the Gerasimov - Caputo and Riemann - Liouville types. With the help of computer experiments, the convergence of finite-difference schemes was shown and estimates of the computational accuracy of the method were obtained, oscillograms and phase trajectories were constructed. However, the questions of stability and convergence were not formulated in the form of corresponding theorems.

From the analysis of the above publications on the study of hereditary oscillator, we can conclude that the main tool for their study is numerical methods, for example, finitedifference schemes. In most cases, the authors leave without attention the questions of stability and convergence of finite-difference schemes, and even if they touch, then without formulating the corresponding theorems and proofs. Therefore, the goal of the present paper is to construct a finite-difference scheme for a wide class of hereditary (fractal) linear and nonlinear oscillators, and to prove its stability and convergence, formulate results in the form of corresponding theorems, and study finite-difference schemes on specific test examples.

\section{Formulation of the Problem}

Consider the following model integro-differential equation for the function $x(t) \in$ $C^{3}(0, T)$, where $T>0$ :

$$
\int_{0}^{t} K_{1}(t-\eta) \ddot{x}(\eta) d \eta+\lambda \int_{0}^{t} K_{2}(t-\eta) \dot{x}(\eta) d \eta=f(x(t), t),
$$

where $\ddot{x}(t)=d^{2} x / d t^{2}, \dot{x}(t)=d x / d t, \lambda>0$ - given constant, functions $K_{1}(t-\eta)$ and $K_{2}(t-\eta)$ - difference kernels in equation (1) will be called memory functions, since they define the notion of heredity (memory) [1].

Equation (1) describes a wide class of hereditary, depending on the form of the righthand side (function $f(x(t), t)$ ) of linear or non-linear oscillators.

Definition 1. A nonlinear function $f(x(t), t)$ on the right-hand side of equation (1) satisfies a Lipschitz condition with respect to a variable $x(t)$ :

$$
\left|f\left(x_{1}(t), t\right)-f\left(x_{2}(t), t\right)\right| \leq L\left|x_{1}(t)-x_{2}(t)\right|,
$$

$L$ - Lipschitz constant.

Вестник ЮУрГУ. Серия «Математическое моделирование

и программирование» (Вестник ЮУрГУ ММП). 2018. Т. 11, № 2. С. 108-122 
Equation (1) describes a broad class of hereditary nonlinear oscillators, depending on the form of the function $f(x(t), t)$ on its right-hand side and the parameter $\lambda$ have the meaning of the coefficient of friction.

Remark 1. Note that the memory functions $K_{1}(t-\eta)$ and $K_{2}(t-\eta)$ can be chosen arbitrarily, depending on the conditions of the particular problem. We will choose these functions power-law, since power laws are often found in various fields of knowledge [11].

We choose the memory functions $K_{1}(t-\eta)$ and $K_{2}(t-\eta)$ in the form:

$$
K_{1}(t-\eta)=\frac{(t-\eta)^{1-\beta(t)}}{\Gamma(2-\beta(t))}, K_{2}(t-\eta)=\frac{(t-\eta)^{-\gamma(t)}}{\Gamma(2-\gamma(t))}
$$

where $\gamma(t), \beta(t) \in C[0, T], \Gamma(t)$ - Euler-gamma function.

Taking into account relation (3) we obtain the following definition.

Definition 2. Derivatives of fractional variables of orders $\beta(t)$ and $\gamma(t)$ Gerasimov Caputo type we call the following operators of fractional differentiation:

$$
\partial_{0 t}^{\beta(t)} x(\eta)=\frac{1}{\Gamma(2-\beta(t))} \int_{0}^{t} \frac{\ddot{x}(\eta) d \eta}{(t-\eta)^{\beta(t)-1}}, \partial_{0 t}^{\gamma(t)} x(\eta)=\frac{1}{\Gamma(1-\gamma(t))} \int_{0}^{t} \frac{\dot{x}(\eta) d \eta}{(t-\eta)^{\gamma(t)}} .
$$

Remark 2. We note that in the case when the functions $\beta(t)$ and $\gamma(t)$ in the relations (4) are constants, we arrive at the definitions of the fractional derivative in the sense of Gerasimov - Caputo [12] and in the case when these constants $\beta=2$ and $\gamma=1$ the operators of fractional differentiation (4) become classical derivatives of the second and first orders.

Taking into account Definition 2 the model equation (1) can be rewritten in a more compact form:

$$
\partial_{0 t}^{\beta(t)} x(\eta)+\lambda \partial_{0 t}^{\gamma(t)} x(\eta)=f(x(t), t) .
$$

For equation (5), the initial conditions in the local formulation are valid:

$$
x(0)=\alpha_{0}, \dot{x}(0)=\alpha_{1},
$$

where $\alpha_{0}$ and $\alpha_{1}$ - given constants. As a result, we arrive at the Cauchy problem (5) and (6), which we will investigate.

\section{Explicit Finite-Difference Scheme}

We construct an explicit finite-difference scheme for the Cauchy problem (5), (6). We divide the time interval $[0, T]$ into $N$ equal parts with a step $\tau=T / N$. We introduce the grid function $x\left(t_{k}\right)=x_{k}$, where $t_{k}=k \tau, k=1, \ldots, N-1$. The derivatives of the variables of fractional orders in equation (5) are approximated according to the relations in [12]:

$$
\partial_{0 t}^{\beta(t)} x(\eta) \approx A_{k} \sum_{j=0}^{k-1} a_{j, k}\left(x_{k-j+1}-2 x_{k-j}+x_{k-j-1}\right)
$$




$$
\partial_{0 t}^{\gamma(t)} x(\eta) \approx B_{k} \sum_{j=0}^{k-1} b_{j, k}\left(x_{k-j+1}-x_{k-j-1}\right)
$$

where the weight coefficients have the form: $a_{j, k}=(j+1)^{2-\beta_{k}}-j^{2-\beta_{k}}, b_{j, k}=(j+1)^{1-\gamma_{k}}-$ $j^{1-\gamma_{k}}, A_{k}=\frac{\tau^{-\beta_{k}}}{\Gamma\left(3-\beta_{k}\right)}, B_{k}=\frac{\lambda \tau^{-\gamma_{k}}}{2 \Gamma\left(2-\gamma_{k}\right)}$. Here to shorten the record: $\beta\left(t_{k}\right)=\beta_{k}$, $\gamma\left(t_{k}\right)=\gamma_{k}$

Taking into account relations (7), the Cauchy problem (5), (6) in the difference formulation will have the form:

$$
A_{k} \sum_{j=0}^{k-1} a_{j, k}\left(x_{k-j+1}-2 x_{k-j}+x_{k-j-1}\right)+B_{k} \sum_{j=0}^{k-1} b_{j, k}\left(x_{k-j+1}-x_{k-j-1}\right)=f_{k}
$$

where $x_{0}=\alpha_{0}, x_{1}=\alpha_{1}+\tau \alpha_{0}$. Here to shorten the record $f_{k}=f\left(x_{k}, t_{k}\right)$. We write the problem (8) explicitly:

$$
\begin{gathered}
x_{k+1}=\frac{1}{A_{k}+B_{k}}\left(2 A_{k} x_{k}-\left(A_{k}-B_{k}\right) x_{k-1}\right)- \\
-\frac{A_{k}}{A_{k}+B_{k}} \sum_{j=1}^{k-1} a_{j, k}\left(x_{k-j+1}-2 x_{k-j}+x_{k-j-1}\right)-\frac{B_{k}}{A_{k}+B_{k}} \sum_{j=1}^{k-1} b_{j, k}\left(x_{k-j+1}-x_{k-j-1}\right)+f_{k} .
\end{gathered}
$$

We note that the weight coefficients $a_{j, k}$ and $b_{j, k}$ have properties, which we formulate in the form of the following lemmas.

Lemma 1. For any $k$ weights coefficients $a_{j, k}, b_{j, k}$, as well as coefficients $A_{k}, B_{k}$ have the following properties:

1) $\sum_{j=0}^{k-1} a_{j, k}=k^{2-\beta_{k}}, \quad \sum_{j=0}^{k-1} b_{j, k}=k^{1-\gamma_{k}}$

2) $1=a_{0, k}>a_{1, k}>\ldots>0,1=b_{0, k}>b_{1, k}>\ldots>0$,

3) $A_{k} \geq 0, B_{k} \geq 0$.

Proof. The first property follows from the definition of weight coefficients. The second property is proved in the following way. We introduce two functions: $\varphi(x)=(x+1)^{2-\beta_{k}}-$ $x^{2-\beta_{k}}$ and $\eta(x)=(x+1)^{1-\gamma_{k}}-x^{1-\gamma_{k}} \eta(x)=(x+1)^{1-\gamma}-x^{1-\gamma}$, where $x>0$. These functions are decreasing. Really derived from these functions:

$$
\varphi^{\prime}(x)=\left(2-\beta_{k}\right)\left[(x+1)^{1-\beta_{k}}-x^{1-\beta_{k}}\right]<0, \eta^{\prime}(x)=\left(1-\gamma_{k}\right)\left[(x+1)^{1-\gamma_{k}}-x^{1-\gamma_{k}}\right]<0 .
$$

Therefore, the second property holds. The third property follows also the properties of the gamma function. The lemma is proved.

Let $\bar{\partial}_{0 t}^{\beta(t)} x(\eta)$ and $\bar{\partial}_{0 t}^{\gamma(t)} x(\eta)$ be the approximations of differential operators of Gerasimov - Kaputo type (7) for $\partial_{0 t}^{\beta(t)} x(\eta)$ and be the $\partial_{0 t}^{\gamma(t)} x(\eta)$, Then we have the following lemma.

Lemma 2. Approximations $\bar{\partial}_{0 t}^{\beta(t)} x(\eta)$ and $\bar{\partial}_{0 t}^{\gamma(t)} x(\eta)$ operators of the Gerasimov - Caputo type $\partial_{0 t}^{\beta(t)} x(\eta)$ and $\partial_{0 t}^{\gamma(t)} x(\eta)$ satisfy the following estimates:

$$
\left|\partial_{0 t}^{\beta(t)} x(\eta)-\bar{\partial}_{0 t}^{\beta(t)} x(\eta)\right| \leq C_{1} \tau,\left|\partial_{0 t}^{\gamma(t)} x(\eta)-\bar{\partial}_{0 t}^{\gamma(t)} x(\eta)\right| \leq C_{2} \tau
$$


where $C_{1}$ and $C_{2}$ - constants that are independent of the parameter $\tau$.

Proof. Using the first property of Lemma 1 and Definition 2, we obtain:

$$
\begin{gathered}
\bar{\partial}_{0 t}^{\beta(t)} x(\eta)=\frac{\tau^{2-\beta_{k}}}{\Gamma\left(3-\beta_{k}\right)} \sum_{j=0}^{k-1} a_{j, k}\left[\ddot{x}(t-j \tau)+O\left(\tau^{2}\right)\right]=\frac{\tau^{2-\beta_{k}}}{\Gamma\left(3-\beta_{k}\right)} \sum_{j=0}^{k-1} a_{j, k} \ddot{x}(t-j \tau)+ \\
+\frac{\tau^{2-\beta_{k}} k^{2-\beta_{k}}}{\Gamma\left(3-\beta_{k}\right)} O\left(\tau^{2}\right)=\frac{\tau^{2-\beta_{k}}}{\Gamma\left(3-\beta_{k}\right)} \sum_{j=0}^{k-1} a_{j, k} \ddot{x}(t-j \tau)+\frac{t^{2-\beta_{k}}}{\Gamma\left(3-\beta_{k}\right)} O\left(\tau^{2}\right)= \\
=\frac{\tau^{2-\beta_{k}}}{\Gamma\left(3-\beta_{k}\right)} \sum_{j=0}^{k-1} a_{j, k} \ddot{x}(t-j \tau)+O\left(\tau^{2}\right) .
\end{gathered}
$$

Similar estimates can be obtained for the operator $\partial_{0 t}^{\gamma(t)} x(\eta)$.

Proposition 1. According to Lemma 2, it can be shown that the explicit finite-difference scheme (9) has an error $\varepsilon=O(\tau)$. This fact will be used in computer experiments in determining the computational accuracy of the numerical method.

The finite-difference scheme (9) can be rewritten in matrix form

$$
\begin{gathered}
X_{k+1}=M X_{k}+F_{k}, \\
X_{k+1}=\left(x_{1}, x_{2}, \ldots, x_{N-1}\right)^{T}, X_{k}=\left(x_{0}, x_{1}, \ldots, x_{N-2}\right)^{T}, F_{k}=\left(f_{0}, f_{1}, \ldots, f_{N-2}\right)^{T},
\end{gathered}
$$

where the matrix $M=\left(m_{i j}\right), i=1, \ldots, N-1, j=1, \ldots, N-1$ :

$$
\begin{gathered}
m_{i j}=\left\{\begin{array}{c}
0, \quad j \geq i+1, \\
\frac{A_{i-1}\left(2-a_{i-2, i-1}\right)-B_{i-1} b_{i-2, i-1}}{A_{i-1}+B_{i-1}}, \quad j=i=3, \ldots, N-1, \\
\frac{-A_{i-1}\left(a_{i-j+1, i-1}-2 a_{i-j, i-1}+a_{i-j-1, i-1}\right)-B_{i-1}\left(b_{i-j+1, i-1}-b_{i-j-1, i-1}\right)}{A_{i-1}+B_{i-1}}, j \leq i-1,
\end{array}\right. \\
m_{1,1}=1, m_{2,2}=\frac{2 A_{1}}{A_{1}+B_{1}}, m_{i, 1}=\frac{B_{i-1} b_{i-2, i-1}-A_{i-1} a_{i-2, i-1}}{A_{i-1}+B_{i-1}}, i=2, \ldots, N-1, \\
m_{i, 2}=\frac{A_{i-1}\left(2 a_{i-2, i-1}-a_{i-3, i-1}\right)+B_{i-1} b_{i-3, i-1}}{A_{i-1}+B_{i-1}}, i=3, \ldots, N-1 .
\end{gathered}
$$

Theorem 1. An explicit finite-difference scheme (9) converges with the first order $\left|\bar{x}_{k}-x_{k}\right|=O(\tau)$ if the following condition is satisfied:

$$
\tau \leq \tau_{0}=\min \left(1,\left(\frac{2 \Gamma\left(2-\gamma_{i-1}\right)}{\lambda \Gamma\left(3-\beta_{i-1}\right)}\right)^{\frac{1}{\beta_{i-1}-\gamma_{i-1}}}\right), i=2, \ldots, N-1
$$

Proof. Let be $\bar{X}_{k}=\left(\bar{x}_{0}, \ldots, \bar{x}_{N-2}\right)^{T}$ the exact solution of system (8) and the error vector $e_{k+1}=\bar{X}_{k+1}-X_{k+1}, e_{0}=0$. Then system (11), with allowance for Lemma 2, can be written as follows:

$$
e_{k+1}=M e_{k}+F_{e, k}+O(\tau),
$$


where, $\quad F_{e, k}=\frac{1}{A_{k}+B_{k}}\left(\left|f\left(x_{1}, t_{k}\right)-f\left(\bar{x}_{1}, t_{k}\right)\right|, \ldots,\left|f\left(x_{k}, t_{k}\right)-f\left(\bar{x}_{k}, t_{k}\right)\right|\right)^{T} \leq$ $\frac{1}{A_{k}+B_{k}}\left(L_{1} e_{1}, \ldots, L_{k} e_{k}\right)=\Delta F_{k} e_{k}, \Delta F_{k}=\frac{1}{A_{k}+B_{k}} \operatorname{diag}\left(L_{1}, \ldots, L_{k}\right)^{T}$. We note that for any $k$ the inequality holds $\left|L_{k}\right| \leq L$ (2). Consider the norm for the matrix $M$ : $\|M\|_{\infty}=\max _{i}\left(\sum_{j=1}^{k-1} m_{i j}\right)$. According to Lemma 1, we note that the inequality holds $\|M\|_{\infty} \rightarrow 1$. Note that for the values of the parameter $\lambda \gg 1$ the norm $\|M\|_{\infty} \rightarrow 1$, however, the condition number $\mu \gg 1$ and is violated and the diagonal transformation is violated, therefore it is necessary to decrease the step $\tau$.

Further from equation (13), for any constant $C>0$ independent of $\tau$, and the error rate, the following estimate holds:

$$
\left\|e_{k+1}\right\|_{\infty} \leq\left\|\Delta F_{k}+M\right\|_{\infty}\left\|e_{k}\right\|_{\infty}+C \tau \leq\left(3+\frac{L}{A_{k}+B_{k}}\right)\left\|e_{k}\right\|_{\infty}+C \tau
$$

We introduce the notation in (14): $s_{k}=\left(3+\frac{L}{A_{k}+B_{k}}\right), s=C \tau$. Then we obtain the following estimate:

$$
\begin{gathered}
\left\|e_{k+1}\right\|_{\infty} \leq s_{k}\left\|e_{k}\right\|_{\infty}+s \leq s_{k}\left(s_{k-1}\left\|e_{k-1}\right\|_{\infty}+s\right)+s= \\
=s_{k} s_{k-1}\left\|e_{k-1}\right\|_{\infty}+s\left(s_{k}+1\right) \leq s_{k} s_{k-1}\left(s_{k-2}\left\|e_{k-2}\right\|_{\infty}+s\right)+s\left(s_{k}+1\right)= \\
=s_{k} s_{k-1} s_{k-2}\left\|e_{k-2}\right\|_{\infty}+s\left(s_{k} s_{k-1}+s_{k}+1\right) \leq \\
\leq s_{k} s_{k-1} s_{k-2}\left(s_{k-3}\left\|e_{k-3}\right\|_{\infty}+s\right)+s\left(s_{k} s_{k-1}+s_{k}+1\right)= \\
=s_{k} s_{k-1} s_{k-2} s_{k-3}\left\|e_{k-3}\right\|_{\infty}+s\left(s_{k} s_{k-1} s_{k-2}+s_{k} s_{k-1}+s_{k}+1\right) \leq \\
\leq s_{k} s_{k-1} \cdots s_{k-r}\left\|e_{k-r}\right\|+s\left(s_{k} s_{k-1} \cdots s_{k-r+1}+\cdots+s_{k}+1\right) .
\end{gathered}
$$

Substituting into (15) $r=k-1$, we obtain:

$$
\left\|e_{k+1}\right\|_{\infty} \leq s_{k} s_{k-1} \cdot \ldots \cdot s_{1}\left\|e_{1}\right\|+s\left(s_{k} s_{k-1} \cdot \ldots \cdot s_{2}+\ldots+s_{k}+1\right) \leq C_{0}\left\|e_{0}\right\|+O(\tau) .
$$

From the second initial condition (6) it follows: $\left\|e_{1}\right\| \leq\left\|e_{0}\right\|$ and $C_{0}=\prod_{p=1}^{k} s_{p}$.

Now according to our assumption $A_{i-1} \geq B_{i-1}$, which leads us to the relation:

$$
\tau \leq\left(\frac{2 \Gamma\left(2-\gamma_{i-1}\right)}{\lambda \Gamma\left(3-\beta_{i-1}\right)}\right)^{\frac{1}{\beta_{i-1}-\gamma_{i-1}}}, i=2, \ldots, N-1 .
$$

The condition (16) begins to work at such values $\lambda$, when a many of conditionality arises $\mu \gg 1$, and for sufficiently small values $\lambda$, it suffices that the step satisfy the inequality $\tau \leq 1$. Therefore, we arrive at the relation (12). The theorem is proved.

Remark 3. We note that in [13] the authors used the classical Lax theorem, which holds for local finite-difference schemes, to prove the convergence of the scheme. For nonlocal finite-difference schemes, the convergence must be proved independently.

We consider the stability of an explicit finite-difference scheme (4). Suppose that $X_{k}$ and two $Y_{k}$ different solutions of the matrix equation (11) with initial conditions $X_{0}$ and $Y_{0}$. 
Theorem 2. An explicit finite-difference scheme (9) is conditionally stable if condition (12) is satisfied and the estimate holds $\left|Y_{k}-X_{k}\right| \leq C\left|Y_{0}-X_{0}\right|$ for any $k$, where $>0$ it does not depend on the step $\tau$.

Proof. We introduce the notation: $e_{k+1}=Y_{k+1}-X_{k+1}$. Then equation (12) can be written in the form: $e_{k+1}=M e_{k}+F_{e, k}$. Here, as it was said in

$$
\begin{gathered}
F_{e, k}=\frac{1}{A_{k}+B_{k}}\left(\left|f\left(x_{1}, t_{k}\right)-f\left(\bar{x}_{1}, t_{k}\right)\right|, \ldots,\left|f\left(x_{k}, t_{k}\right)-f\left(\bar{x}_{k}, t_{k}\right)\right|\right)^{T} \leq \\
\leq \frac{1}{A_{k}+B_{k}}\left(L_{1} e_{1}, \ldots, L_{k} e_{k}\right)=\Delta F_{k} e_{k} .
\end{gathered}
$$

According to Theorem 1, we have the following estimate:

$$
\left\|M+\Delta F_{k}\right\| \leq\left(3+\frac{L}{A_{k}+B_{k}}\right)=s_{k}
$$

Therefore, the following estimate holds:

$$
\begin{gathered}
\left\|e_{k+1}\right\|_{\infty} \leq\left\|M+\Delta F_{k}\right\|\left\|e_{k}\right\|_{\infty} \leq\left(3+\frac{L}{A_{k}+B_{k}}\right)\left\|e_{k}\right\|_{\infty}= \\
=s_{k}\left\|e_{k}\right\|_{\infty} \leq s_{k} s_{k-1}\left\|e_{k-1}\right\|_{\infty} \leq s_{k} s_{k-1} s_{k-2}\left\|e_{k-2}\right\|_{\infty} \leq \ldots \leq s_{k} s_{k-1} \cdot \ldots \cdot s_{k-r}\left\|e_{k-r}\right\| . \\
\text { With } r=k-1 \text {, we obtain }\left\|e_{k+1}\right\|_{\infty} \leq{ }_{0}\left\|e_{1}\right\| \leq C_{0}\left\|e_{0}\right\|, C_{0}=\prod_{p=1}^{k} s_{p} .
\end{gathered}
$$

The last inequality follows from the second condition of problem (6). Therefore, if $X_{0}$ there is a perturbation, then it does not lead to a large increase in the error of the numerical solution. However, for large values $\lambda$, a many of conditionality $\mu \gg 1$ arises, and therefore it is necessary to decrease the step $\tau$, according to (16), for small values $\lambda$ the estimate is valid $\tau \leq 1$. Then the system is stable if condition (12) is satisfied. The theorem is proved.

\section{Results of Modelling}

Consider the work of the explicit finite-difference scheme (9) on specific examples. We show that the scheme (9) has the first order of accuracy. Since in the general case the exact solution of the Cauchy problem (5), (6) can't be written in the analytical form, we will use the double conversion method. For this, we introduce two parameters: $\xi=\max _{i}\left|x_{i}-x_{2 i}\right|$ - absolute error between the numerical solution $x_{i}$ in step $\tau$ and the numerical solution $x_{2 i}$ in step $\tau / 2$. Then the order of computational accuracy $p$ can be estimated by formula: $p=$ $\log _{2}(\xi) / \log _{2}(\tau / 2)$. The numerical algorithm (9) was developed in a computer programme in the language of symbolic mathematics Maple.

Remark 4. We note that in the case when the fractional parameters in the scheme (9) do not change and have the following values of $\beta_{k}=2$ and $\gamma_{k}=1$, we arrive at the classical local explicit finite-difference scheme with the second order of accuracy. 
Example 1. Suppose that the right-hand side in equation (1) has the form:

$$
f(x(t), t)=\delta \sin (\varphi t)+t x(t) .
$$

Then equation (5) describes a linear hereditary Airy oscillator, which was considered in the author's papers [7] and has the following form:

$$
\partial_{0 t}^{\beta(t)} x(\eta)+\lambda \partial_{0 t}^{\gamma(t)} x(\eta)-t x(t)=\delta \cos (\varphi t) .
$$

We choose the initial conditions (6) for simplicity by homogeneous: $x(0)=\dot{x}(0)=0$ In this case, the explicit finite-difference scheme (9) has a more specific form $\left(x_{0}=x_{1}=0\right)$ :

$$
\begin{gathered}
x_{k+1}=\frac{1}{A_{k}+B_{k}}\left(\left(2 A_{k}-k \tau\right) x_{k}-\left(A_{k}-B_{k}\right) x_{k-1}+\delta \sin (\varphi k \tau)\right)- \\
-\frac{A_{k}}{A_{k}+B_{k}} \sum_{j=1}^{k-1} a_{j, k}\left(x_{k-j+1}-2 x_{k-j}+x_{k-j-1}\right)-\frac{B_{k}}{A_{k}+B_{k}} \sum_{j=1}^{k-1} b_{j, k}\left(x_{k-j+1}-x_{k-j-1}\right) .
\end{gathered}
$$

For the explicit finite-difference scheme (17), we choose the following values of the control parameters: $T=1, \lambda=1, \delta=5, \varphi=10, \omega=10, \beta(t)=1,8-0,03 \sin (\omega t), \gamma(t)=$ $0,8-0,05 \cos (\omega t)$ and during the simulation we will change the number of nodes $N$ in the calculation grid.

Remark 5. We note that for Example 1 the conditions of Theorem 1 and Theorem 2 are satisfied, which is indirectly confirmed by the results of modelling for different values $N$ of the nodes of the computational grid (Table 1 ).

\section{Table 1}

Results of numerical simulation

\begin{tabular}{|c|c|c|}
\hline$N$ & $\xi$ & $p$ \\
\hline 640 & 0,0003331017 & 1,119146497 \\
\hline 1280 & 0,0001745618 & 1,102636795 \\
\hline 2560 & 0,0000906971 & 1,089811915 \\
\hline
\end{tabular}

From Table 1 we can notice that when the number of calculated nodes in the grid doubles in nodes $N$, the maximum error in absolute value decreases twice, and the order of computational accuracy $p$ tends to unity.

This confirms that the explicit finite-difference scheme (9) and in particular the scheme (17) for Example 1 has the first order of accuracy, and since condition (12) is satisfied, then convergence with the same order.

In Fig. 1 the oscillogram (Fig. 1 a) and the phase trajectory (Fig. 1 b) are shown for Example 1 at the parameter value $T=10, N=1000$. It can be noted that with time the amplitude of the oscillations is established and as a result the phase trajectory reaches the limit cycle. Another situation arises in the case of free oscillations $\delta=0$ (Fig. 2).

The amplitude of the oscillations decays (Fig. 2 a), and the phase trajectory twists into a spiral (Fig. 2 b). The dissipation of energy in this case occurs as a result of the presence of friction with a coefficient $\lambda$, and also the "memory" effect, which gives an additional term in the ratio for the total energy of the oscillatory system (Fig. 3). This fact is confirmed by the results of [2]. Consider the following example of a nonlinear hereditary oscillator. 


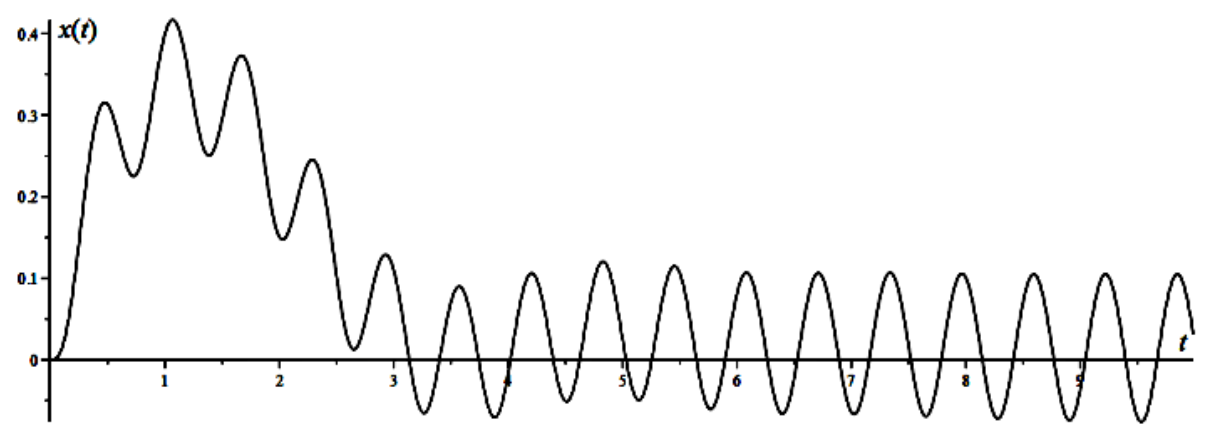

a)

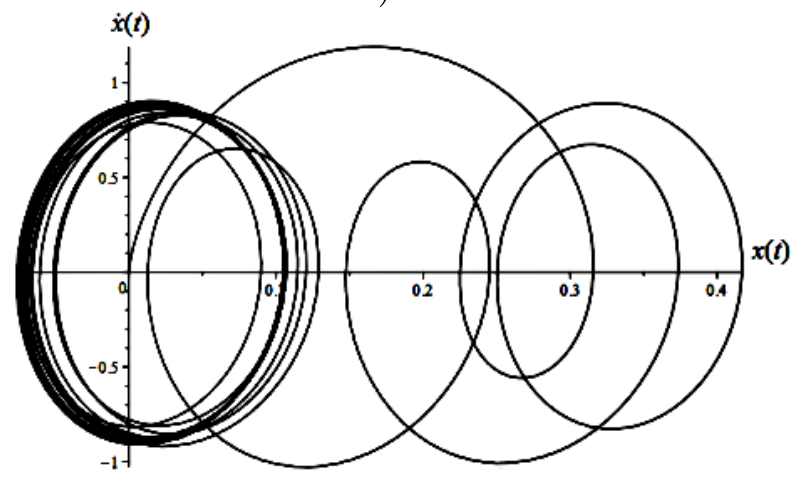

b)

Fig. 1. The oscillogram $a$ ) and the phase trajectory $b$ ) for Example 1 with the parameter values $T=10, N=1000$

Example 2. Let the right-hand side in equation (1) has the form:

$$
f(x(t), t)=\delta \sin (\varphi t)-a x(t)+b x^{3}(t),
$$

and we choose the homogeneous initial conditions $(6): x(0)=\dot{x}(0)=0$. In this case, Equation. (5) describes the Duffing fractional oscillator [5]:

$$
\partial_{0 t}^{\beta(t)} x(\eta)+\lambda \partial_{0 t}^{\gamma(t)} x(\eta)+b x^{3}(t)-a x(t)=\delta \sin (\varphi t)
$$

The explicit finite-difference scheme (9) for this case has the form $\left(x_{0}=x_{1}=0\right)$ :

$$
\begin{gathered}
x_{k+1}=\frac{1}{A_{k}+B_{k}}\left(\left(2 A_{k}+1\right) x_{k}-x_{k}^{3}-\left(A_{k}-B_{k}\right) x_{k-1}+\delta \sin (\varphi k \tau)\right)- \\
-\frac{A_{k}}{A_{k}+B_{k}} \sum_{j=1}^{k-1} a_{j, k}\left(x_{k-j+1}-2 x_{k-j}+x_{k-j-1}\right)-\frac{B_{k}}{A_{k}+B_{k}} \sum_{j=1}^{k-1} b_{j, k}\left(x_{k-j+1}-x_{k-j-1}\right) .
\end{gathered}
$$

For the explicit finite-difference scheme (18), we take the values of the control parameters as follows: $T=1, \lambda=0,3, \delta=2, \varphi=\omega=1$.

Remark 6. Note that this choice of control parameter values is ensured by the condition (12) for Theorem 1 and Theorem 2.

The results of numerical simulation for Example 2 are given in Table 2.

Note from Table 2 that for Example 2, with an increase in the number of design nodes $N$, the maximum error $\xi$ in absolute value decreases, and the order of computational 

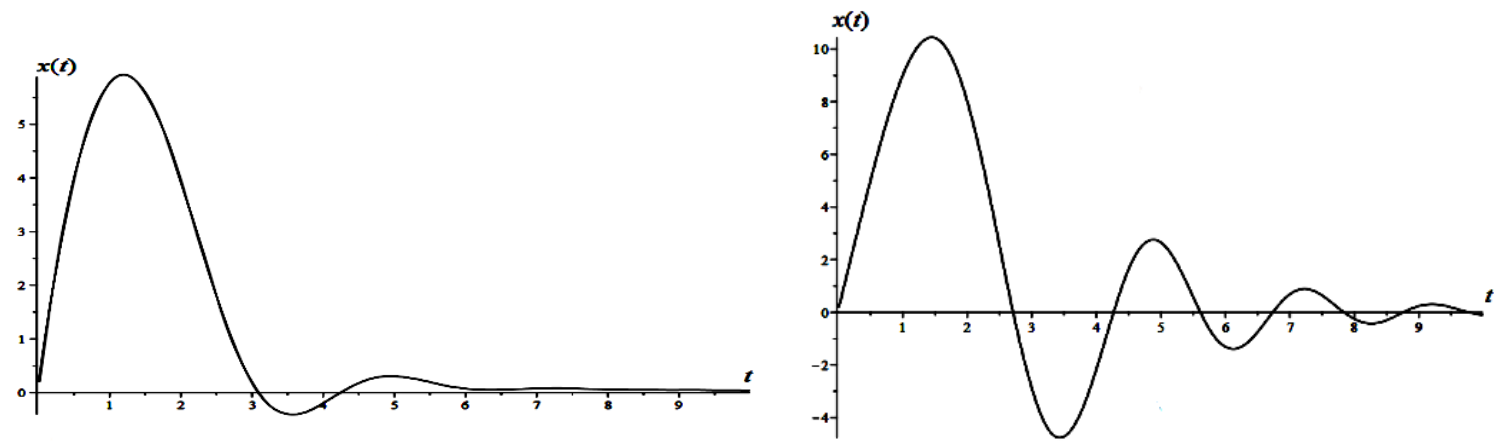

a)
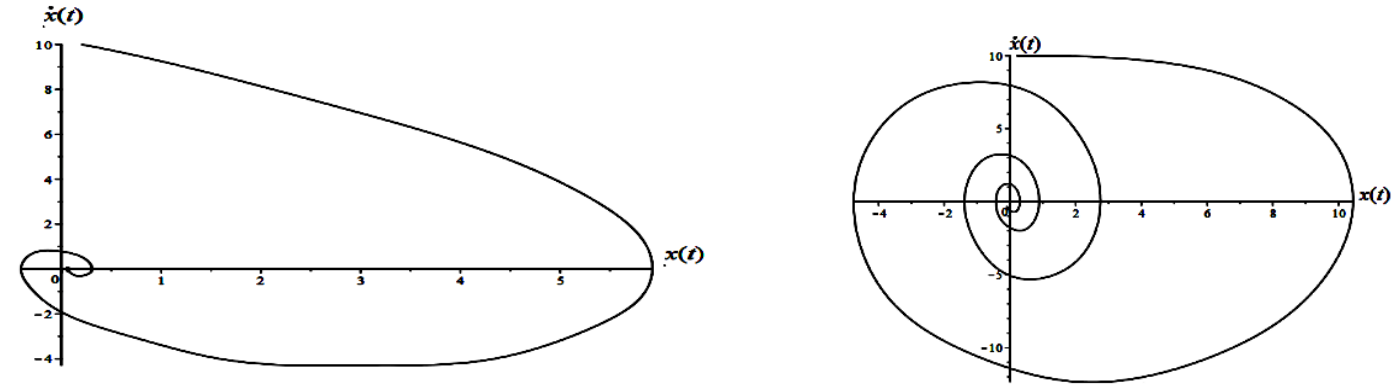

b)

Fig. 2. The oscillogram a) and the phase trajectory b) for Example 1 with initial conditions $x(0)=0,1, \dot{x}(0)=0,2$ and $\delta=0$ this is the left figure and right figure for $\lambda=0$

Table 2

Results of numerical simulation

\begin{tabular}{|c|c|c|}
\hline$N$ & $\xi$ & $p$ \\
\hline 640 & 0,0003619281 & 1,107545912 \\
\hline 1280 & 0,0001896841 & 1,092050182 \\
\hline 2560 & 0,0000991471 & 1,079382204 \\
\hline
\end{tabular}

accuracy $p$ tends to unity. This indicates that the explicit finite-difference scheme (18) has the first order of accuracy. Let's perform numerical simulation according to the scheme (18) with the values of the following parameters: $T=100, N=2000, \delta=50$, and leave the remaining parameters unchanged. Let us construct an oscillogram and a phase trajectory (Fig. 3).

The oscillogram (Fig. 4 a) has a constant amplitude of a more complex shape at its minima and maxima, which is reflected in the phase trajectory (Fig. 4 b). The phase trajectory enters a complex two-loop limit cycle. The presence of such loops, apparently, is associated with the effects of memory in the oscillatory system.

Fig. 4 shows the case of free oscillations for Example 2. It is seen that the presence of friction and memory effects in the oscillatory system intensify energy dissipation, which leads to damping of the oscillations (Fig. 4 a) and a phase trajectory a twisting spiral (Fig. $4 \mathrm{~b}$ ). Indeed, if there is no friction $\lambda=0$ in the oscillatory system, we obtain an oscillogram and a phase trajectory. 


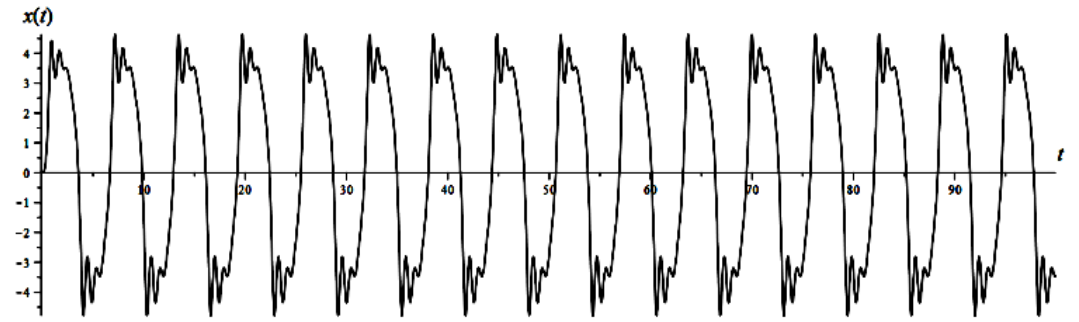

a)

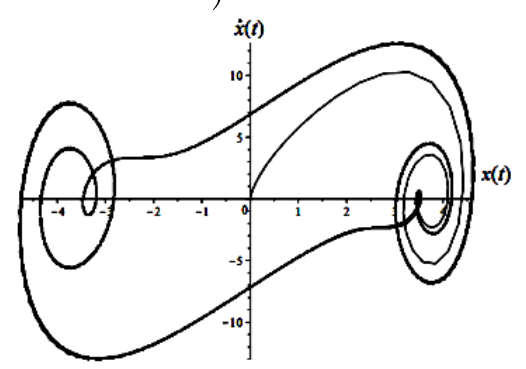

b)

Fig. 3. The oscillogram a) and the phase trajectory b) for Example 2
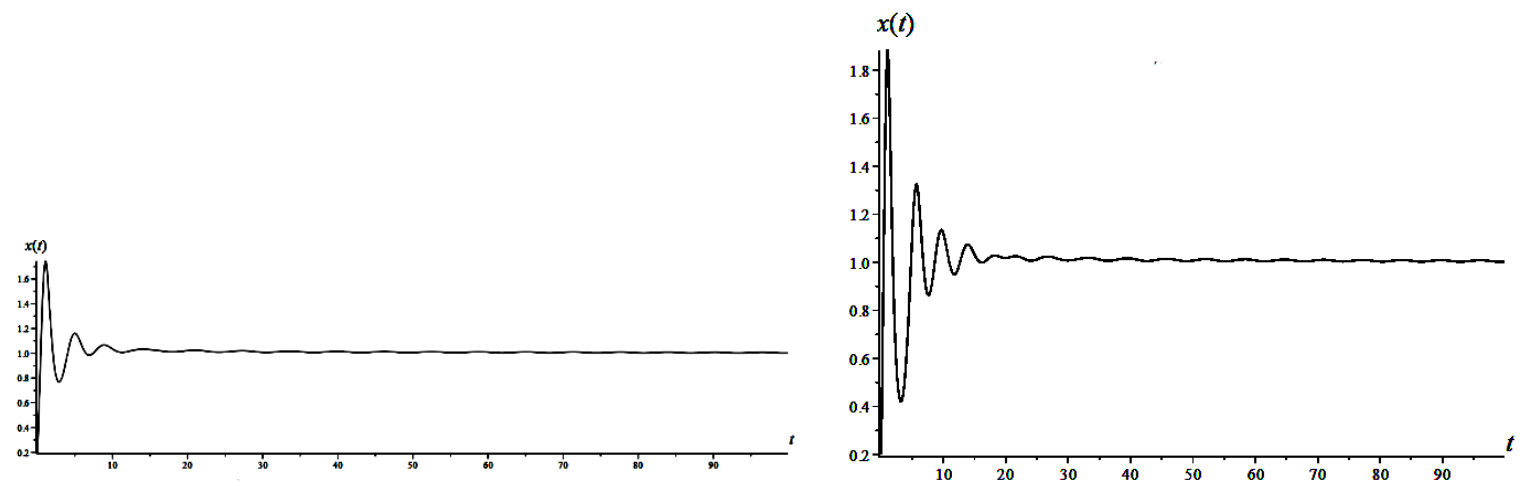

a)
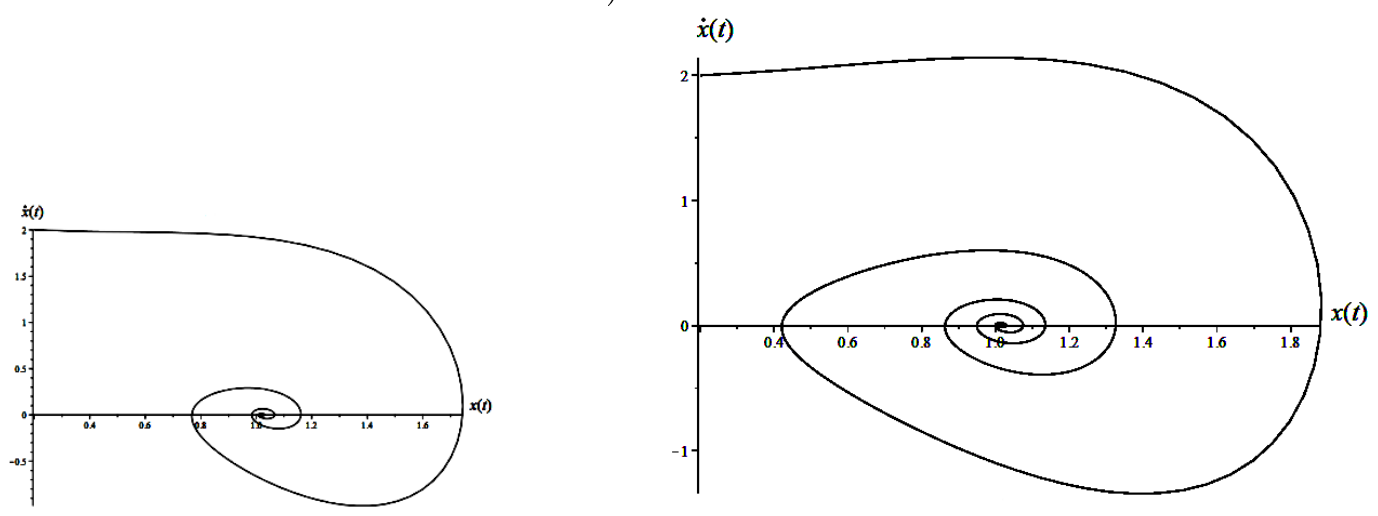

b)

Fig. 4. Oscillogram a) and phase trajectory b) for Example 2 with initial conditions $x(0)=0,1, \dot{x}(0)=0,2$ and $\delta=0$ this is the left figure and right figure for $\lambda=0$ 
Example 3. Suppose that in the equation (1) the right-hand side has the form:

$$
f(x(t), t)=b t+c \sum_{n=1}^{7} a_{n} \sin (n x(t))-\omega^{\beta(t)} x(t),
$$

where $b$ is spring travel speed, $c$ is the surface adhesion energy, $\omega$ is the frequency of free oscillations, $a_{n}=2 n \int_{0}^{1} \frac{\cos (\pi n \tau) d \tau}{\cosh ^{2}(\pi \tau)}$ are coefficients of the expansion of the Fourier series.

Equation (5) with the right-hand side of (19) describes the hereditary stick-slip effect [6]. The values of these coefficients are taken from: $a_{1}=0,436, a_{2}=0,344, a_{3}=0,164, a_{4}=$ $0,058, a_{5}=0,021, a_{6}=0,004, a_{7}=0,003$. Values of control parameters: $\beta(t)=1,8-$ $0,03 \sin (\pi t), \gamma(t)=0,6-0,04 \cos (\pi t), N=3000, \delta=50, \tau=0,05, \lambda=0,3, b=1$, $\omega=1, x(0)=0, \dot{x}(0)=0,3$.

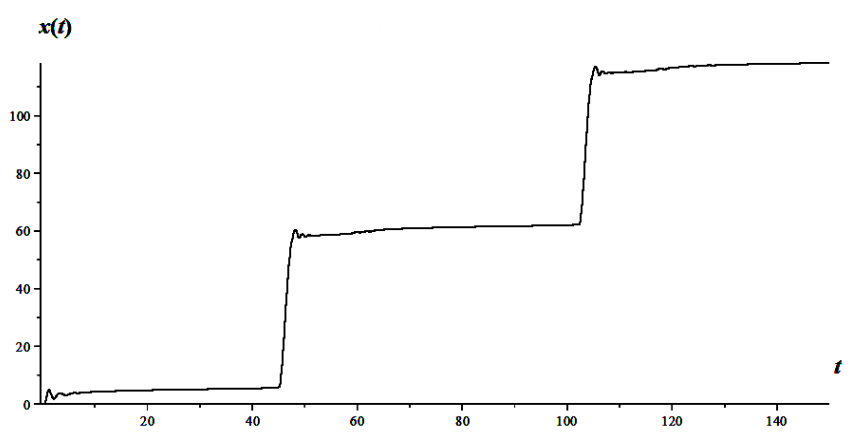

a)

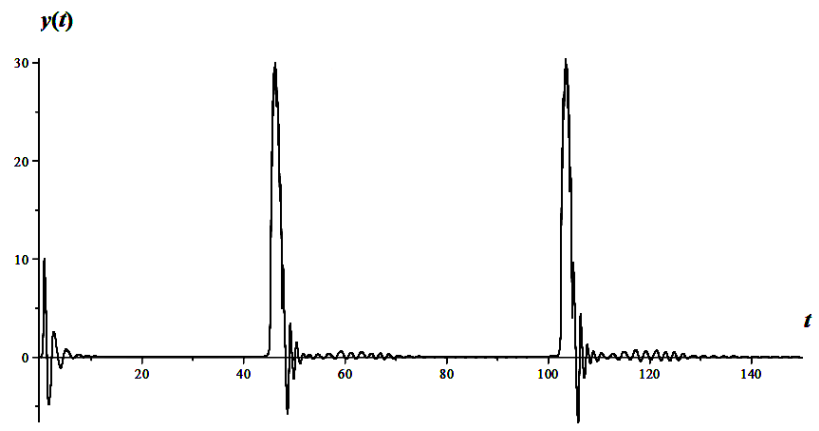

b)

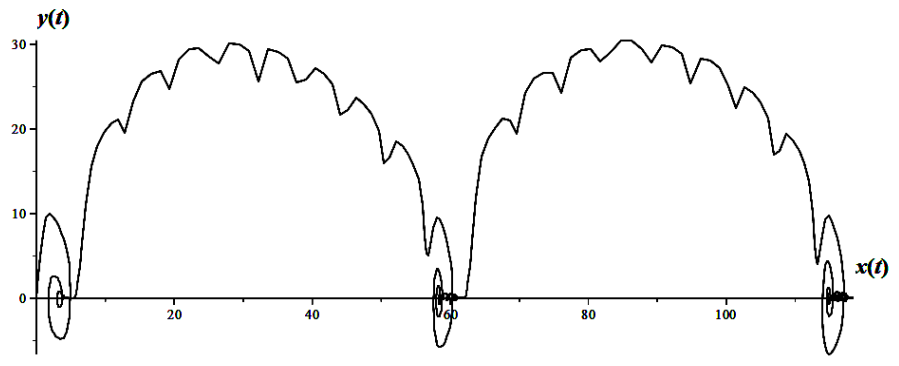

c)

Fig. 5. Calculated curves obtained from formula (9): a) oscillogram, b) oscillator speed, c) phase trajectory 
Fig. 5 shows the calculated displacement curves, displacement velocities and phase trajectory. Fig. 5 a shows the oscillogram for Example 3. It can be seen that during the separation, the load experiences oscillations, and the rate of such oscillations in the potential well attenuates rather slowly Fig. $5 \mathrm{~b}$. This effect is the eradication of the process. The phase trajectory Fig. 5 c shows that the potential wells are stable focuses.

\section{Conclusion}

A mathematical model characterizing a wide class of hereditary oscillators is proposed and studied. The model is a differential Cauchy problem with derivatives of fractional order variables of the Gerasimov - Kaputo type (5), (6). Using the theory of finite-difference schemes, a non-local explicit finite-difference scheme (9) was constructed with the first order of accuracy. Questions of its stability and convergence, which are formulated in the form of corresponding theorems, were studied.

The main result of the paper can be formulated as follows: an explicit finite-difference scheme is conditionally stable and converges if criterion (12) is satisfied. With the help of computational examples it was shown that the scheme (9) has the first order of accuracy. It is confirmed that in the case of free oscillations, the presence of friction and heredity increases dissipation of energy, which leads to attenuation of oscillations.

Acknowledgements. The work was carried out according to the state task the framework of a scientific research work of Kamchatka State University named after Vitus Bering on the topic "Application of fractional calculus in the theory of oscillatory processes" No. AAAA-A17-117031050058-9 and with the support of the grant of the President of the Russian Federation MK-1152.2018.1.

\section{References}

1. Volterra V. Sur les equations integro-differentielleset leurs applications. Acta Mathematica, 1912, vol. 35, no. 1, pp. 295-356. DOI: 10.1007/BF02418820

2. Mainardi F. Fractional Relaxation-Oscillation and Fractional Diffusion-Wave. Chaos, Soliton and Fractal, 1996, vol. 7, no. 9, pp. 1461-1477. DOI: 10.1016/0960-0779(95)00125-5

3. Petras I. Fractional-Order Nonlinear Systems. Modeling, Analysis and Simulation. Berlin, Heidelberg, Springer, 2011. DOI: 10.1007/978-3-642-18101-6

4. Xu Y., Agrawal O.P. Models and Numerical Solutions of Generalized Oscillator Equations. Journal of Vibration and Acoustics, 2014, vol. 136, Article ID 051005. DOI: 10.1115/1.4027241

5. Parovik R.I. Mathematical Modeling of Nonlocal Oscillatory Duffing System with Fractal Friction. Bulletin KRASEC. Physical and Mathematical Sciences, 2015, vol. 10, no. 1, pp. $16-21$.

6. Parovik R.I. On a Credit Oscillatory System with the Inclusion of Stick-Slip. E3S Web of Conferences, 2016, vol. 11, Article ID 00018.

7. Parovik R.I. Mathematical Modelling of Hereditarity Airy Oscillator with Friction. Bulletin of the South Ural State University. Series: Mathematical Modelling, Programming and Computer Software, 2017, vol. 10, no. 1, pp. 138-148. DOI: 10.14529/mmp170109

8. Kim V.A. Duffing Oscillator with External Harmonic Action and Variable Fractional Riemann - Liouville Derivative Character - Izing Viscous Friction. Bulletin KRASEC. Physical and Mathematical Sciences, 2016, vol. 13, no. 2, pp. 46-49. 
9. Lipko O.D. Mathematical Model of Propagation of Nerve Impulses with Regard Hereditarity. Bulletin KRASEC. Physical and Mathematical Sciences, 2017, vol. 16, no. 1, pp. 33-43.

10. Kilbas A.A., Srivastava H.M., Trujillo J.J. Theory and Applications of Fractional Differential Equations. Amsterdam, Elsevier, 2006.

11. Schroeder M. Fractals, Chaos, Power Laws: Minutes from an Infinite Paradise. New York, W.H. Freeman, 1991.

12. Parovik R.I. Explicit Finite-Difference Scheme for the Numerical Solution of the Model Equation of Nonlinear Hereditary Oscillator with Variable-Order Fractional Derivatives. Archives of Control Sciences, 2016, vol. 26, no. 3, pp. 429-435. DOI: 10.1515/acsc-2016-0023

13. Xu Y., Erturk V.S. A Finite Difference Technique for Solving Variable-Order Fractional Integro-Differential Equations. Bulletin of the Iranian Mathematical Society, 2014, vol. 40, no. 3, pp. 699-712.

Received February 14, 2018

УДК 517.925.42

DOI: $10.14529 / \mathrm{mmp} 180209$

\section{МАТЕМАТИЧЕСКАЯ МОДЕЛЬ ШИРОКОГО КЛАССА ОСЦИЛЛЯТОРОВ С ПАМЯТЬЮ}

P.И. Паровик, Камчатский государственный университет имени В. Беринга, г. Петропавловск-Камчатский, Российская Федерация; Институт космофизических исследований и распространения радиоволн ДВО РАН, с. Паратунка, Камчатский край, Российская Федерация

В работе предложена математическая модель для описания широкого класса эредитарньх осцилляторов или осцилляторов с памятью. В качестве базового уравнения в такой модели выступает интегро-дифференциальное уравнения вольтеровского типа с разностными ядрами - функциями памяти, которые были выбраны степенными функциями. Этот выбор, с одной стороны, обусловлен широкими приложениями степенных законов и фрактальными свойствами процессов в природе, а с другой, дает возможность применить математический аппарат дробного исчисления. Далее, в работе модельное интегро-дифференциальное уравнение было записано в терминах производных дробных порядков Герасимова - Капуто. Используя аппроксимации операторов дробных порядков, была составлена нелокальная явная конечно-разностная схема, которая дает численное решение предложенной модели. С помощью лемм и теорем сформулированы условия устойчивости и сходимости полученной схемы. Приведены примеры работы численного алгоритма для некоторых эредитарных осцилляторов, построены их осциллограммы и фазовые траектории.

Ключевые слова: математическая модель; задача Коии; эредитарность; производная дробного порядка; конечно-разностная схема; устойчивость; сходимость; осииллограммы; базовые траектории. 


\section{Литература}

1. Volterra, V. Sur les Equations Integro-Differentielleset Leurs Applications / V. Volterra // Acta Mathematica. - 1912. - V. 35, № 1. - P. 295-356.

2. Mainardi, F. Fractional Relaxation-Oscillation and Fractional Diffusion-Wave F. Mainardi // Chaos, Soliton \& Fractal. - 1996. - V. 7, № 9. - P. 1461-1477.

3. Petras, I. Fractional-Order Nonlinear Systems. Modeling, Analysis and Simulation / I. Petras. - Berlin; Heidelberg: Springer, 2011.

4. Xu, Y. Models and Numerical Solutions of Generalized Oscillator Equations / Y. Xu, O.P. Agrawal // Journal of Vibration and Acoustics. - 2014. - V. 136. - Article ID 051005.

5. Parovik, R.I. Mathematical Modeling of Nonlocal Oscillatory Duffing System with Fractal Friction / R.I. Parovik // Bulletin KRASEC. Physical and Mathematical Sciences. - 2015. V. 10, № 1. - P. 16-21.

6. Parovik, R.I. On a Credit Oscillatory System with the Inclusion of Stick-Slip / R.I. Parovik // E3S Web of Conferences. - 2016. - V. 11. - Article ID 00018.

7. Паровик, Р.И. Математическое моделирование эредитарного осциллятора Эйри с трением / Р.И. Паровик // Вестник ЮУрГУ. Серия: Математическое моделирование и программирование - 2017. - Т. 10, № 1. - С. 138-148.

8. Kim, V.A. Duffing Oscillator with External Harmonic Action and Variable Fractional Riemann - Liouville Derivative Character - Izing Viscous Friction / V.A. Kim // Bulletin KRASEC. Physical and Mathematical Sciences. - 2016. - V. 13, № 2. - P. 46-49.

9. Lipko, O.D. Mathematical Model of Propagation of Nerve Impulses with Regard Hereditarity / O.D., Lipko // Bulletin KRASEC. Physical and Mathematical Sciences. - 2017. - V. 16, № 1. - P. 33-43.

10. Kilbas, A.A.Theory and Applications of Fractional Differential Equations / A.A. Kilbas, H.M. Srivastava, J.J. Trujillo. - Amsterdam: Elsevier, 2006.

11. Schroeder, M. Fractals, Chaos, Power Laws: Minutes from an Infinite Paradise M. Schroeder. - N.Y.: W.H. Freeman, 1991.

12. Parovik, R.I. Explicit Finite-Difference Scheme for the Numerical Solution of the Model Equation of Nonlinear Hereditary Oscillator with Variable-Order Fractional Derivatives / R.I. Parovik // Archives of Control Sciences. - 2016. - V. 26, № 3. - P. 429-435.

13. Xu, Y. A Finite Difference Technique for Solving Variable-Order Fractional IntegroDifferential Equations / Y. Xu , V.S. Erturk // Bulletin of the Iranian Mathematical Society.2014. - V. 40, № 3. - P. 699-712.

Роман Иванович Паровик, кандидат физико-математических наук, доцент, доцент кафедры математики и физики, Камчатский государственный университет имени Витуса Беринга (г. Петропавловск-Камчатский, Российская Федерация); старший научный сотрудник лаборатории «Математическое моделирование физических процессов», Институт космофизических исследований и распространения радиоволн ДВО РАН (с. Паратунка, Камчатский край, Российская Федерация), romanparovik@gmail.com.

Поступила в редакчию 14 февраля 2018 г. 